\title{
Peroxisomal Acyl-CoA Oxidase Type 1: Anti-Inflammatory and Anti-Aging Properties with a Special Emphasis on Studies with LPS and Argan Oil as a Model Transposable to Aging
}

\author{
Joseph Vamecq $\mathbb{D}^{1}{ }^{1}$ Pierre Andreoletti $\mathbb{D}^{2},{ }^{2}$ Riad El Kebbaj, ${ }^{3}$ Fatima-Ezzahra Saih, ${ }^{2,4}$ \\ Norbert Latruffe, ${ }^{2} M^{\prime}$ Hammed Saïd El Kebbaj, ${ }^{5}$ Gérard Lizard, ${ }^{2}$ Boubker Nasser, ${ }^{3}$ \\ and Mustapha Cherkaoui-Malki $\mathbb{D i D}^{2}$ \\ ${ }^{1}$ INSERM, HMNO, CBP, CHRU and RADEME EA 7364, Faculté de Médecine, Université Lille 2, Lille, France \\ ${ }^{2}$ Laboratoire BioPeroxIL (Biochimie du Peroxysome, Inflammation et Métabolisme Lipidique) EA 7270/Inserm, Université \\ Bourgogne-Franche Comté, Dijon, France \\ ${ }^{3}$ Laboratoire des Sciences et Technologies de la Santé, Institut Supérieur des Sciences de la Santé, Université Hassan Premier, \\ Settat, Morocco \\ ${ }^{4}$ Laboratoire de Biochimie et Neurosciences, Faculté des Sciences et Techniques, Université Hassan I, Settat, Morocco \\ ${ }^{5}$ Laboratoire de recherche sur les lipoprotéines et l'Athérosclérose, Faculté des Sciences Ben M'sik, Université Hassan II-Mohammedia- \\ Casablanca, Casablanca, Morocco
}

Correspondence should be addressed to Joseph Vamecq; joseph.vamecq@inserm.fr and Mustapha Cherkaoui-Malki; mustapha.cherkaoui-malki@u-bourgogne.fr

Received 29 September 2017; Accepted 23 January 2018; Published 25 March 2018

Academic Editor: Javier Egea

Copyright ( 2018 Joseph Vamecq et al. This is an open access article distributed under the Creative Commons Attribution License, which permits unrestricted use, distribution, and reproduction in any medium, provided the original work is properly cited.

To clarify appropriateness of current claims for health and wellness virtues of argan oil, studies were conducted in inflammatory states. LPS induces inflammation with reduction of PGC1- $\alpha$ signaling and energy metabolism. Argan oil protected the liver against LPS toxicity and interestingly enough preservation of peroxisomal acyl-CoA oxidase type 1 (ACOX1) activity against depression by LPS. This model of LPS-driven toxicity circumvented by argan oil along with a key anti-inflammatory role attributed to ACOX1 has been here transposed to model aging. This view is consistent with known physiological role of ACOX1 in yielding precursors of specialized proresolving mediators (SPM) and with characteristics of aging and related disorders including reduced PGC1- $\alpha$ function and improvement by strategies rising ACOX1 (via hormonal gut FGF19 and nordihydroguaiaretic acid in metabolic syndrome and diabetes conditions) and SPM (neurodegenerative disorders, atherosclerosis, and stroke). Delay of aging to resolve inflammation results from altered production of SPM, SPM improving most aging disorders. The strategic metabolic place of ACOX1, upstream of SPM biosynthesis, along with ability of ACOX1 preservation/induction and SPM to improve aging-related disorders and known association of aging with drop in ACOX1 and SPM, all converge to conclude that ACOX1 represents a previously unsuspected and currently emerging antiaging protein.

\section{Introduction}

Vegetal compounds and oils are current trends for active research. One reason lies in the consideration that nature forms a whole and may provide living beings with both pathogenic and curative factors. Beside vegetal poisons [1], some vegetal compounds as for instance those extracted from Digitalis purpurea and Camptotheca acuminata tree may be therapeutically active $[2,3]$ or in turn may serve as guide compounds for medicinal chemistry design in cardiovascular disorders and cancer. It remains currently unclear whether, however, such real curative medical indications may be attributed as a general rule to the bulk of vegetal-derived compounds or oils endowed with health-improving properties. In this respect, argan oil is currently becoming largely acclaimed for a large variety of health and wellness virtues 
$[4,5]$. The anti-inflammatory potential of argan oil has been recently addressed by evaluating its effects towards the highly inflammatory LPS using a murine model of sepsis [6]. In this disorder, peroxisomal Acyl-CoA oxidase 1 (ACOX1) was preserved by argan oil against inactivation by LPS in the same time as the oil protected the liver against most of LPS-driven toxicity and metabolic homeostasis disruption [6]. On the other hand, ACOX1 initiates the peroxisomal pathway ensuring retroconversion of polyunsaturated fatty acids [7]. Key role of ACOX1 in biosyntheses of eicosanoids (E series) and docosanoids (D series) further yielding specialized proresolving mediators (SPM) (resolvins, neuroprotectins, and maresins) $[8,9]$ is stressed along with preserved or increased ACOX1 activity in models of diabetes and metabolic syndromes. The alterations in SPM production and their roles as potential therapeutic candidates in many other pathological states linked to aging such as neurodegenerative disorders (e.g., Alzheimer's disease), macular degeneration, and vascular disorders (stroke, atherosclerosis, and mitochondrial dysfunction in senescent brain) are further developed.

Olive oil contains about $70 \%$ oleic acid while argan oil harbors $45 \%$ oleic acid and 35\% linoleic acid, indicating that argan oil is richer in polyunsaturated fatty acids [10]. Early studies on argan oil revealed its beneficial effects on lipid metabolism and antioxidant status through drops in plasma low density lipoprotein-cholesterol (LDL-cholesterol) and lipoperoxides, along with a rise in plasma tocopherol concentration [11]. In this respect, argan oil contains a high level of antioxidant compounds including gamma-tocopherol and also ferulic acid which exhibit ROS-scavenging and antiinflammatory properties [12]. Cumulated activities of these individual argan oil components meet therapeutic efficacy in humans as attested by the beneficial metabolic effects of argan oil reported in several clinical trials on dyslipidemic markers [11]. Improvements of dyslipidemia by argan oil are consistent with studies on the expression of nuclear genes controlling lipid metabolism which, as highlighted in the next section, have shown in an animal model of human sepsis that argan oil upregulates hepatic expression of PGC-1 $\alpha$, leading to parallel coactivations of the nuclear receptors-PPAR $\alpha, \mathrm{ERR} \alpha$, and $\mathrm{HNF}-4 \alpha$-which govern FAOx metabolism and gluconeogenesis [6].

\section{Studies with Protection by Argan Oil of LPS-Induced Model of Sepsis}

Chronic administration of argan oil prevents liver dysfunction experimentally induced by sepsis-mimicking conditions [6]. This result was obtained in mice exposed to LPS as a model for human sepsis. Preventive protection was observed at reasonable oil diet concentrations (6\%), suggesting a potential applicability of this diet measure in the medical practice. This observation makes chronic argan oil intakes preventive antidotes for sepsis and, hence, might suggest influence of diet backgrounds of patients on sepsis development and prognosis. Whether therapeutic issues may ultimately emerge from administration of this oil, though promising, still remains speculative. Nonetheless, mechanisms by which its administration is capable of blunting sepsis LPS-driven liver dysfunction are remarkable and provide liver with a unique point-to-point reply to various signaling and metabolic targets of sepsis. The various ways altering the capacity of liver engine to fulfill energetic demands of extrahepatic tissues are subject to a suited protection through stimulation or preservation of signaling and metabolic events, which are extinct by sepsis (Figure 1). Part of features enabling LPS to disrupt signaling for liver metabolic support to extrahepatic tissues and prevention by argan oil [6] is illustrated in Figure 1 panels A and B, respectively. The depicted events have been arbitrarily divided in PGC1- $\alpha$-dependent and independent features. LPS negatively impacts signaling for fatty acid oxidation and gluconeogenesis, the two key metabolic pathways enabling liver to aliment extrahepatic tissues in energetic substrates in periods of increased energy demands. PGC- $1 \alpha$-independent LPS features include sterol depletion by LPS leading to the LPS-dependent activation of SREBP1 [13], which in turn enhances gene expression of lipin-1 $[14,15]$. The accumulation of diacylglycerol, which may involve lipin-1, leads to gluconeogenesis impairment through mTOR signaling [16] (Figure 1(a), left part). PGC$1 \alpha$-dependent mechanisms mainly lie in a severe drop in PGC- $1 \alpha$ signaling with resulting loss in PPAR $\alpha$ and HNF$4 \alpha$ signaling (Figure $1(\mathrm{~b})$, right part).

Under LPS, argan oil (Figure 1(b), right part) stimulates PPAR $\alpha$ and PGC- $1 \alpha$ signaling, contributing to stimulate fatty acid oxidation, and via the impact of PGC- $1 \alpha$ acting as a coactivator of $\mathrm{HNF}-4 \alpha$, to preserve gluconeogenesis despite no concomitant drop in lipin-1 signaling by this oil [6]. Under LPS, depression of lipin-1 by olive oil (Figure 1(b), left part) would avoid a negative impact on gluconeogenesis signaling. By contrast to argan oil, olive oil does not fully rescue the LPS-decreased PGC- $1 \alpha$ expression. So, this may prevent the lowering of fatty acid oxidation activity and allows its preservation under exposure to LPS [6]. Figure 2 illustrates that argan and olive oils preserve normal hepatic fatty acid oxidation and gluconeogenesis capacities under LPS. Under LPS, each of the pathologically disrupted steps is preserved under chronic administration of the oils. As highlighted by the figure, oils may be considered as affording a protection highly adapted to the metabolically toxic liver changes induced by LPS.

\section{Transposing to Aging the Sepsis Model of Inflammation Induced by LPS and Resolved by Argan Oil}

The liver metabolic changes and underlying signaling characterizing LPS-induced model of sepsis and counteraction by argan oil have been mentioned and illustrated above. What has been illustrated in Figures 1 and 2 is essentially how the major liver energetic metabolic pathways (gluconeogenesis, mitochondrial fatty acid oxidation) and underlying signaling are modified by LPS and under LPS how argan oil may impact LPS-induced changes. Effects on peroxisomal $\beta$-oxidation, which is not per se an energetic pathway, have not been depicted in these figures. Interestingly enough, one of the toxic effects of LPS on mouse liver metabolism was a 


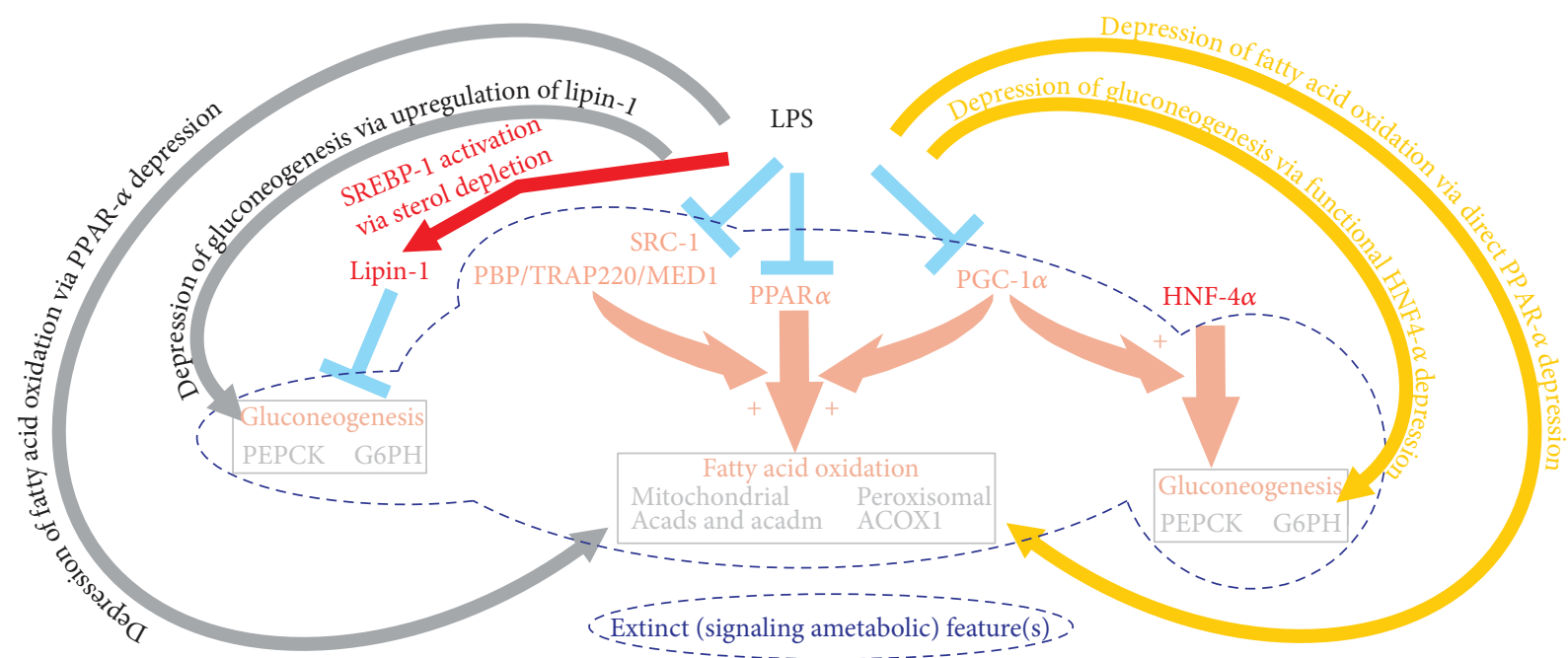

(a)

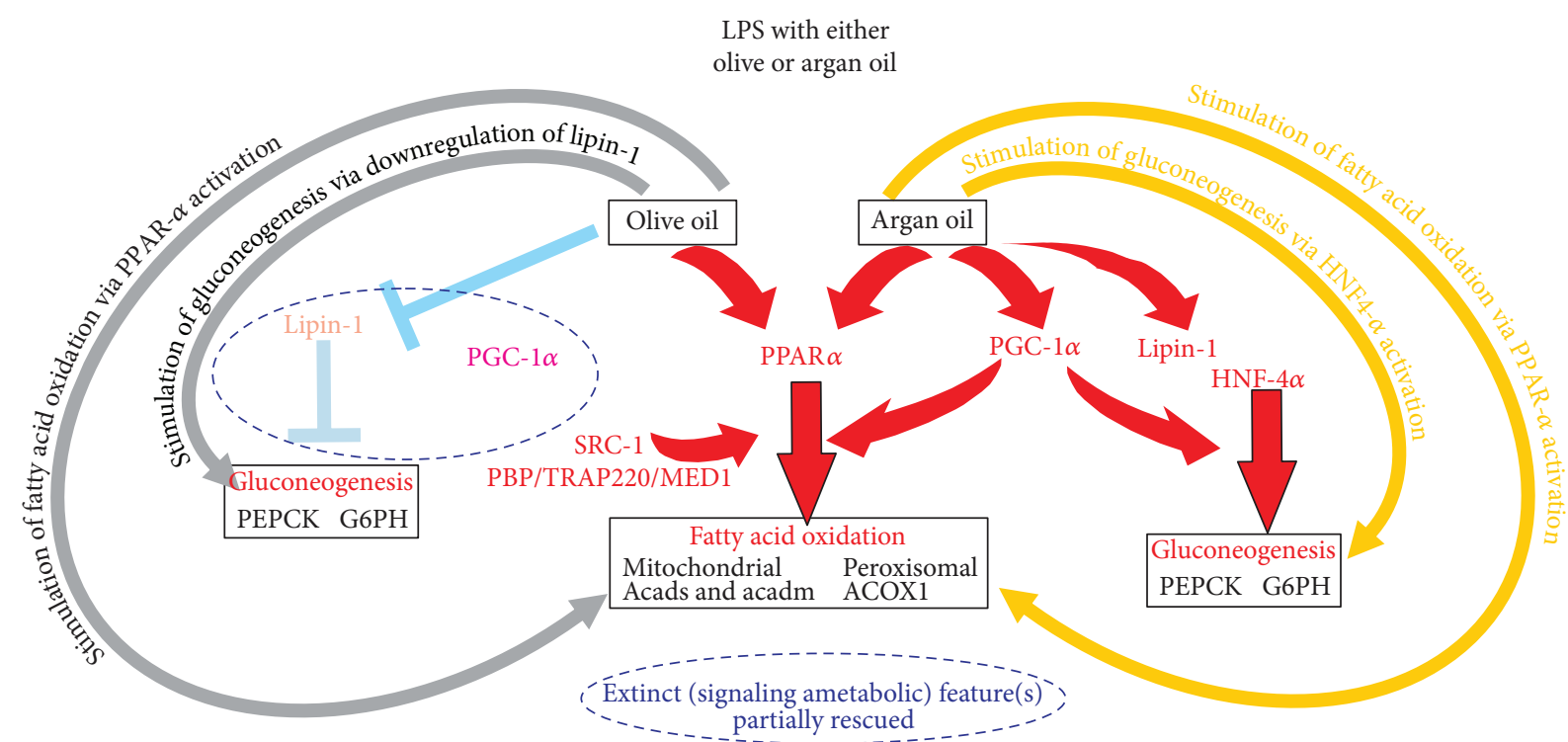

PGC-1 $\alpha$ independent features

PGC-1 $\alpha$ dependent features

(b)

FIgURE 1: Putative impact of LPS on signaling events involved in the regulation of key steps in liver metabolic support of extrahepatic tissues (a) and effective preventive protection conveyed by argan and olive oils (b). LPS and oil effects have been divided into PGC-1 $\alpha$ independent and dependent features. Note that, however, for sake of illustration, the inhibitory action of olive oil on PGC-1 $\alpha$ is artificially placed in the PGC- $1 \alpha$ independent mechanisms subpanel.

significant drop in acyl-CoA oxidase 1 activity [6]. LPSmediated inhibition of peroxisomal $\beta$-oxidation activity was also described in rat liver under experiments focusing on the effect of endotoxin treatment on peroxisomal $\beta$-oxidation enzymology [17]. In this study, peroxisomal $\beta$-oxidation measured as lignoceric oxidation rates and ACOX1 activity was reduced to 56 and $73 \%$ control values, respectively [14]. Argan oil prevented LPS-induced drop of the ACOX1 activity in liver from mice exposed to LPS [6].

Figure 3 is an attempt to model LPS-driven toxicity and protective effect of argan oil with a special emphasis on ACOX1. This representation is interesting because it attributes a key role to ACOX1 in controlling inflammation in a way upstream of the metabolic reprogramming induced by LPS. This reprogramming of energetic metabolism by LPS has been shown to involve depression of PGC- $1 \alpha$ activity $[10,18]$. In our representation appearing in Figure 3(a), this reprogramming of energetic metabolism is induced by inflammation and leads to impairment of ACOX1 explaining that protection (by argan oil) of this enzyme might restore an active control of inflammation and hence a unique opportunity to remove the energy 


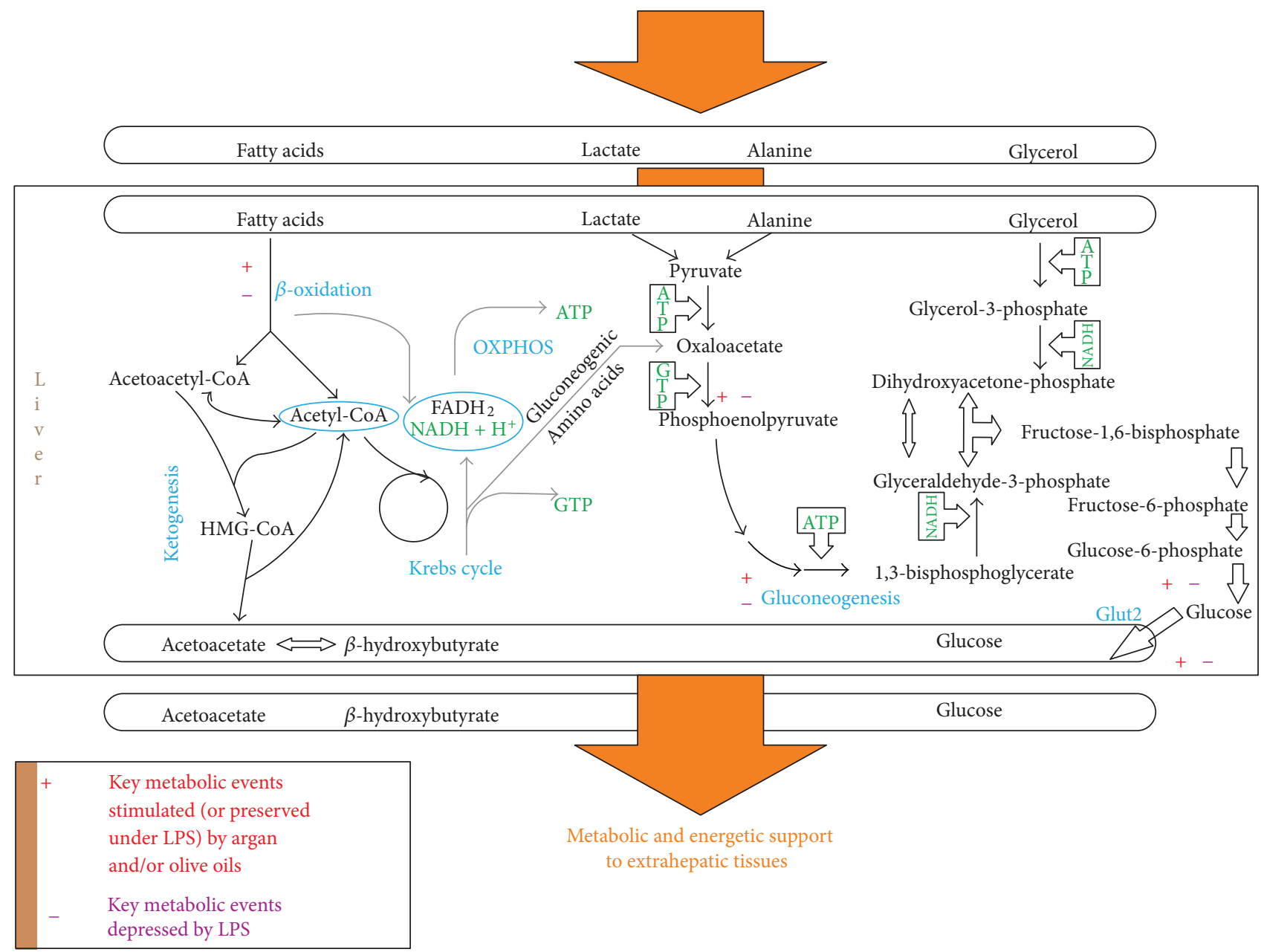

Figure 2: Liver metabolic and energetic support to extrahepatic tissues and its modulation by LPS, and, under LPS, argan and olive oils. Events depicted on this original figure were inferred from data published in [6].

metabolic reprogramming responsible for toxicity (by LPS). In our previous study on mouse model for sepsis, LPS induced a deep drop in PGC- $1 \alpha$; argan oil effectively protected ACOX1 and removed energy metabolic reprogramming as attested by full restitution of PGC-1 $\alpha$ [6].

A remarkable feature is the appropriateness to transpose to aging our model of LPS-driven toxicity and protective effect of argan oil with a special emphasis on ACOX1. This is done and illustrated in Figure 3(b). Like LPS, aging promotes inflammation. It is well accepted that aging is characterized by a delay to resolve inflammation [19]. Another extraordinary parallelism between LPS and aging is the drop in PGC- $1 \alpha$, along with sometimes rescue by a rise in PGC$1 \alpha$, which has been observed and incriminated in aging [20] and the development of many aging-related disorders including obesity and type 2 diabetes [21, 22], coronary diseases [23], neurodegenerative disorders (Alzheimer [24, 25], Parkinson [26-28], and Huntington [29-31] diseases), myocardial infarction [32-37], mitochondrial dysfunction in senescent brain [20,38, 39], and stroke [40-43].

Consistent also with the relevance of the emerging model of aging appearing on Figure 3 are as developed thereafter (i) the remarkable anti-inflammatory potential of ACOX1 through generation of precursors of lipid mediators with potent anti-inflammatory activity (specialized proresolving mediators, SPM), (ii) protection given by either argan oil use or ACOX1 induction in signaling pathways improving diabetes and metabolic syndromes and (iii) protection given by SPM in age-related disorders.

\section{Studies Highlighting that ACOX1 Is Physiologically Involved in the Synthesis of Precursors of Specialized Proresolving Mediators (SPM)}

\subsection{Peroxisomal Acyl-CoA Oxidase 1 in Health and Disease}

4.1.1. LPS Reduces Liver ACOX1 in a Way Counteracted by Oils. One of the toxic effects of LPS on liver metabolism was a significant drop in acyl-CoA oxidase 1 activity [6]. One of the putative protective effects of oils, argan and to a lesser extent olive oil, is prevention of LPS-induced drop in the expression of the peroxisomal protein [6].

4.1.2. ACOX 1 in the Physiology of Peroxisomal $\beta$-Oxidation. Acyl-CoA oxidase 1 (ACOX1) belongs to one of the two 


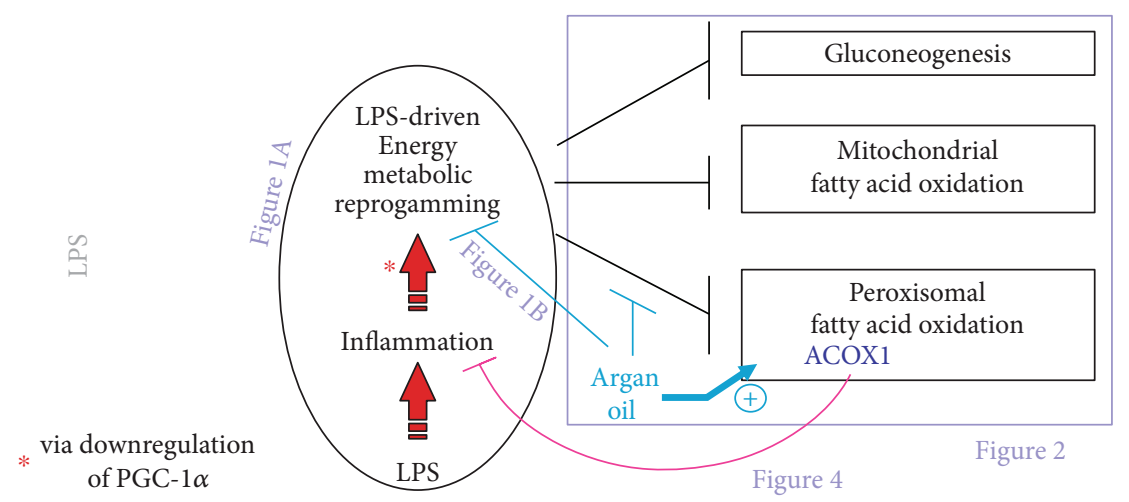

(a)

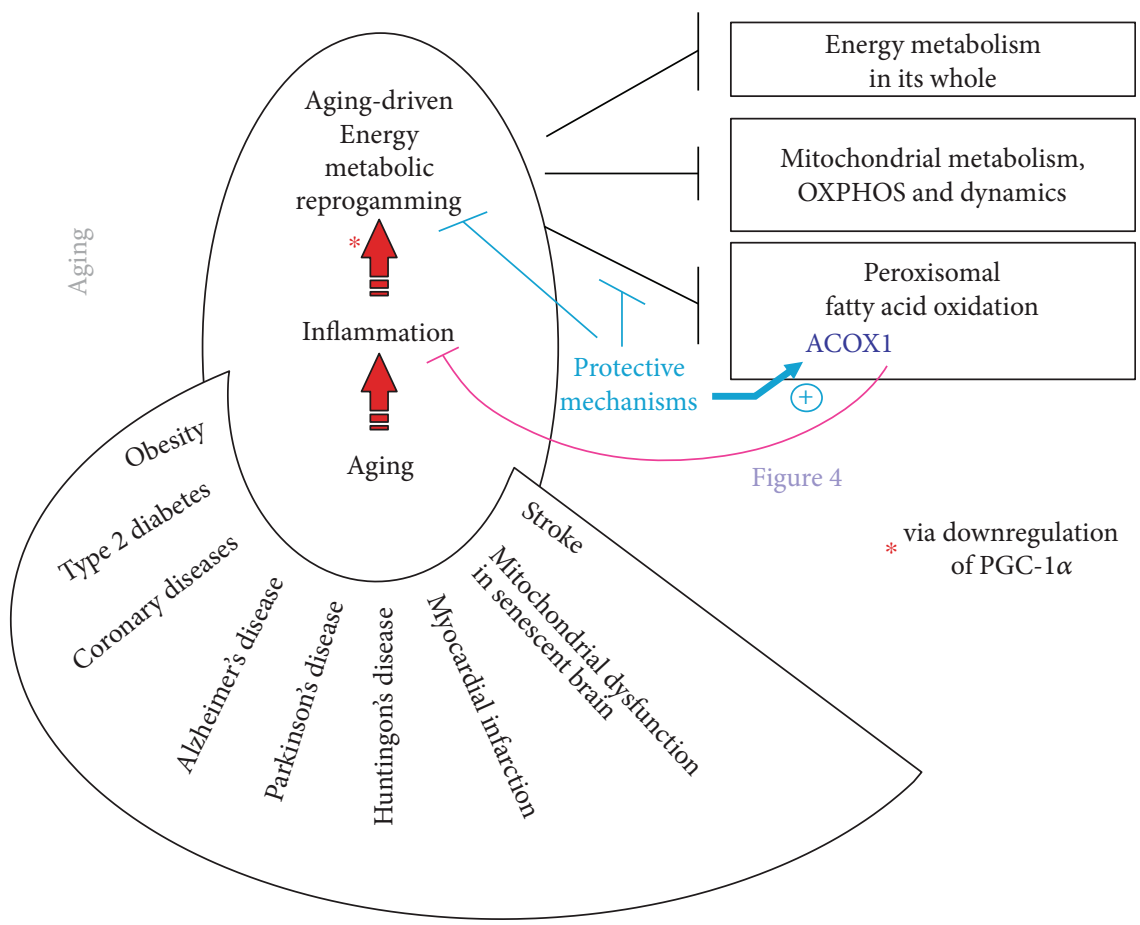

(b)

FIGURE 3: Modelizing the LPS-driven inflammation and counteraction by argan oil with a special emphasis on ACOX1 (a) and transposing this model to aging (b). For both, LPS toxicity and aging-related disorders, models, inflammatory states, and illustrated consequences along with anti-inflammatory ACOX1 and its status in these pathological states are further discussed in the text. The figure also positions other figures of this review.

separate $\beta$-oxidation systems identified in peroxisomes [44]. In the first peroxisomal $\beta$-oxidation system, ACOX1 catalyzes the first and the rate-limiting step of straightchain fatty acids [45]. In contrast, structurally unrelated acyl-CoA oxidases 2 and 3 , of the second peroxisomal $\beta$ oxidation system, metabolize branched-chain fatty acids (pristanic acid) and C27 bile acid precursors, respectively, although in the humans type 2 is the only acyl-CoA oxidase involved in bile acid biosynthesis, and both type 2 and 3 acyl-CoA oxidases are functional on branchedchain fatty acyl-CoA $[44,46]$.

4.1.3. Anti-Inflammatory Potential of ACOX 1. ACOX1, one of the targets of LPS [6], has proven anti-inflammatory properties and, in the context of sepsis, its preservation by oils, under signaling adaptations abundantly developed above, might contribute to liver protection. Anti-inflammatory action of ACOX1 is based on various pathogenesis and physiological pieces of evidence considered thereafter.

(1) ACOX1 Null Mice. Mice lacking ACOX1 manifest severe inflammatory steatohepatitis with increased intrahepatic $\mathrm{H}_{2} \mathrm{O}_{2}$ levels and hepatocellular regeneration [47]. This hepatic oxidative stress may trigger TNF $\alpha$ production by Kupffer cells. Progressively, chronic endoplasmic reticulum stress contributes to hepatocarcinogenesis [48] and this steatotic ACOX1 null phenotype can be reversed by expression of the human ACOX1 $[48,49]$. In the ACOX1-dependent 
hepatocarcinogenesis, the involvement of nuclear receptor PPAR $\alpha$ is essential [50]. In brain lesions of patients with peroxisomal $\beta$-oxidation deficit, oxidative, inflammatory, and apoptotic processes have been described [51]. The expressions of genes coding for cytokines IL-6, IL-8, and TNF $\alpha$, which are typically produced by macrophages and by CD4+ $\mathrm{T}$ cells Th1, have also been found to be increased in ACOX1 deficiency [52]. On the other hand, several cytokines and chemokine mRNAs are strongly downregulated in ACOX1deficient patient fibroblasts, including CXCL14 and CXCL12 genes, which have been shown to participate in the regulation of cell or tissue homeostasis [52]. In this peroxisomal disorder, lipid derivatives with an abnormally high proportion of VLCFA residues have been proposed to trigger the initial cascade of the inflammatory process [53]. The severity of the metabolic disruption associated with peroxisomal ACOX1 deficiency underlines the crucial role of peroxisomes in synthesizing or degrading highly specific metabolites, accumulation or deficit of which may impact peroxisome biogenesis itself and/or collaborative working with other cellular organelles such as mitochondria and endoplasmic reticulum.

(2) Physiological Role of ACOX1 in the Metabolism of Polyunsaturated Fatty Acids (PUFA). Physiological evidence for a key role of ACOX1 in alimenting docosanoid formation (for metabolic steps, elongases and desaturases, of PUFA synthesis considered throughout the text thereafter (see [54]) rests on the key role of this enzyme in the retroconversion of polyunsaturated fatty acids (PUFAs) (Figure 4) [7, 54-59]. For recall, families of PUFAs are characterized by the position of the unsaturation closest to the terminal, so-called $\omega$, methyl of the fatty acid carbon chain. In contrast to the position of the unsaturation towards the carboxylate, that towards the other end of the carbon chain is kept upon elongation or shortening of the carbon chain. Among these families, the $\omega-6$ and $\omega-3$ families are generated from linoleic and $\alpha$-linolenic acids, respectively. The metabolism of these PUFAs is illustrated on Figure 4 and starts with their preliminary activation into CoA esters by acyl-CoA synthetases prior to handling by acyl-CoA desaturases and elongases.

\section{PUFA Desaturases and Elongases}

Acyl-CoA desaturases introduce cis-double bonds between the carboxylate group and the first unsaturation of the carbon chain, at three carbons from this unsaturation. The desaturase(s) acting on $\mathrm{C}_{18}$ and $\mathrm{C}_{24}$ PUFAs is a $\Delta 6$-desaturase and that acting on the $C_{20}$ PUFAs is a $\Delta 5$-desaturase. The latter desaturase produces CoA esters of arachidonic acid or ARA (5,8,11,14-eicosatetraenoic acid) and EPA (5,8,11,14,17-eicosapentaenoic acid). Nonesterified forms of PUFAs are released from phospholipids by PLA2. They are substrates for cyclooxygenases and lipooxygenases, which drive the $\mathrm{C}_{20}$ PUFAs (eicosanoids) towards prostanoids (prostaglandins and thromboxanes) and leukotrienes (plus HPETE, hydroperoxyeicosatetraenoic acids, and HETE, hydroxyeicosatetraenoic acids) syntheses, respectively [60-62]. CoA esters of ARA and EPA not having been incorporated into phospholipids may continue elongation.

\section{PUFA Retroconversion}

Though this view has been recently seriously challenged (see consideration below in the text), mammalian cells are assumed to possess little or no direct PUFA $\Delta 4$-desaturase activity, so the ARA-CoA and EPA-CoA elongation products in $\mathrm{C}_{22}(7,10,13,16$-docosatetraenoyl-CoA [ $\omega 6]$ and 7,20,13, 16,19-docosapentaenoyl-CoA [w3]) would not be immediately desaturated at the $\Delta 4$ position. In order to produce the corresponding $\Delta 4$-desaturated metabolites, cells are capable of operating an additional elongation converting

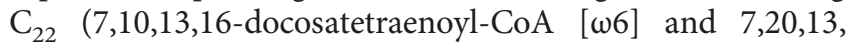

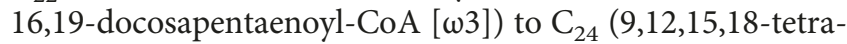
cosatetraenoyl-CoA [ $\omega 6]$ and 9,12,15,18,21-tetracosapentae-

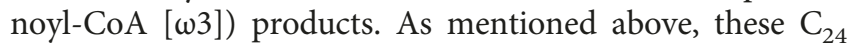
PUFAs are substrates for $\Delta 6$ desaturase. The $\mathrm{C}_{24}$ products desaturated in $\Delta 6(6,9,12,15,18$-tetracosapentaenoyl-CoA

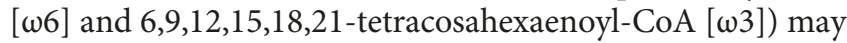
undergo a two-carbon chain shortening which generates $\mathrm{C}_{22}$ PUFAs now presenting with an unsaturation at the $\Delta 4$ position. So, cells may catalyze $\Delta 4$ desaturase activity on the $\mathrm{C}_{22}$ 7,10,13,16-docosatetraenoyl-CoA [w6] and 7,20,13,16,19docosapentaenoyl-CoA [ $[\omega 3]$ by combining elongation in $\mathrm{C}_{24}$-CoA, $\mathrm{C}_{24}$ PUFA-CoA $\Delta 6$ desaturation and $\mathrm{C}_{24} \Delta 6$ PUFA-CoA retroconversion into $\mathrm{C}_{22} \Delta 4$ PUFA-CoA. This $\mathrm{C}_{24}$ to $\mathrm{C}_{22}$ retroconversion corresponds to a peroxisomal $\beta$ oxidizing cycle with two-carbon-chain cleavage. PUFA-CoA desaturation and elongation are catalyzed by microsomal proteins, elongation being also catalyzed by mitochondria.

6.1. Metabolic Intervention of ACOX1 in PUFA Retroconversion. In the scope of PUFA retroconversion, the $\mathrm{C}_{24} \Delta 6$ PUFA$\mathrm{CoA}$ requires import into peroxisomal matrix to which acyl-CoA $\beta$-oxidation enzymes belong. $\mathrm{C}_{24} \Delta 6$ PUFA-CoAs are very long straight chain fatty acyl-CoAs. Transfer through peroxisomal membranes would be here assisted by $\mathrm{ABCD} 2$, which prefers unsaturated very long-chain fatty acids in contrast to $\mathrm{ABCD} 1$, the protein deficient in $\mathrm{X}$ linked adrenoleukodystrophy, which preferentially acts on saturated VLCFA [63]. After import by ABCD2, the peroxisomal $\beta$-oxidation of $\mathrm{C}_{24} \Delta 6$ PUFA-CoAs may proceed with peroxisomal acyl-CoA oxidase 1 (1st $\beta$-oxidation step), Dbifunctional protein (2nd and 3rd $\beta$-oxidation steps), and thiolases 1 and/or 2 (for the 4th and last step) [63]. This unique $\beta$-oxidation turn produces the $\mathrm{C}_{22} \Delta 4$ PUFA-CoAs: DPA $(4,7,10,13,16$-docosapentaenoic acid [ $\omega 6])$ and DHA $(4,7,10,13,16,19$-docosahexaenoic acid [ $\omega 3])$ (DPA without other precision here refers to the n-6 DPA, the retroconversion product of TPA, and not to n-3 DPA, the product elongation of EPA).

\section{Biosynthesis of Anti-Inflammatory Lipid Mediators from PUFAs "Retroconverted" by Peroxisomal ACOX1-Dependent $\beta$-Oxidation}

As highlighted by Figure 4, in the absence of dietary DHA, though ACOX1 would not be needed for the formation of part of the resolvins, namely E series resolvins, it represents an essential step in the biosynthesis of the D-series resolvins, 


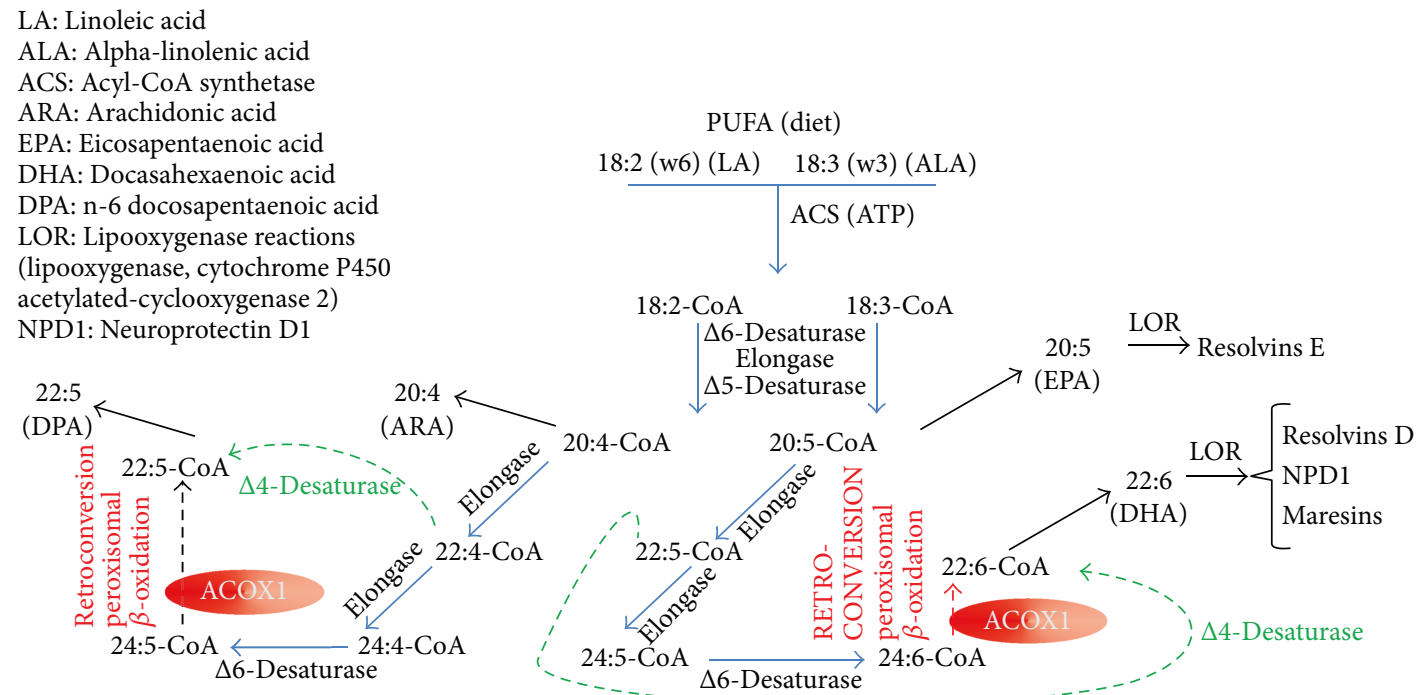

FIGURE 4: Key role of peroxisomal acyl-CoA oxidase 1 in the control of inflammation and as a target of diseases and consequent therapeutic approaches.

neuroprotectins, and maresins as a result of its key role in the retroconversion of PUFAs. On this light, it may be considered that the role of sepsis-mediated inhibition of ACOX1 might have been overlooked in the inflammatory challenge raised by sepsis in liver. In the same time, it may be asked whether protection of ACOX1 has not been also previously overlooked as an important feature in the anti-inflammatory potential conveyed by argan and olive oils.

The anti-inflammatory role of ACOX1 may be linked to its contribution to the yield of anti-inflammatory compounds. In this respect, DHA may be supplied by diet and endogenous biosynthesis. The last step in DHA biosynthesis is PUFA retroconversion which rests on a single peroxisomal ACOX1-initiated $\beta$-oxidation turn. Several works reviewed in [64] argue that resolvins, such as neuroprotectin D1 (NPD1), mediate anti-inflammatory and protective action of n-3 PUFAs in brain disorders. NPD1 is formed from DHA and reduces apoptosis in Alzheimer brain [65], whereas DHA and NPD1 lower transcript levels of the inflammatory gene products COX2 and NF-KB [66]. Protective effects of DHA and metabolites against chronic inflammations including cardiovascular disorders, asthma, rheumatoid arthritis, and inflammatory bowel diseases reviewed in [67] might also stress anti-inflammatory properties of ACOX1. In these studies, ACOX1 was bypassed by direct supplementation of its product (DHA) and derived metabolites (specialized proresolving mediators of the $\mathrm{D}$ series).

7.1. A Subtle Equilibrium between Desaturation, Elongation, and Oxidation of PUFA-CoA Esters. Desaturation and elongation of very long-chain PUFAs share in common with acyl-CoA oxidase 1 their action on CoA esters as substrates. It is likely that a subtle equilibrium exists between a given PUFA-CoA and its partition between the three fatty acid chain remodelling pathways and therefore this metabolic partition might be specific to the considered PUFA. The $\Delta 6$ desaturase involved prior the acyl-CoA oxidase 1-driven retroconversion corresponds to the fatty acid desaturase 2 (FADS2) gene product. Importantly, FADS2 is also responsible for the catalysis of a direct $\Delta 4$-desaturation of ARA and EPA directly to DPA and DHA, thus bypassing the retroconversion step (broken green arrow on Figure 4) [68] and complicating the metabolic partition mentioned above. On the other hand, in an animal model for acyl-CoA oxidase 1 gene $\mathrm{KO}$, accumulation of very long-chain PUFAs were observed, corroborating the role of the peroxisomal oxidase in their retroconversion [69].

\section{Anti-Inflammatory Potential of ACOX1 in Aging-Related Disorders Including Diabetes and Metabolic Syndrome}

The recent advance in the biosynthesis of resolvins and recognition of their targets including various receptors among which GPCRs and also various microRNA (for a recent review, see [70]) has obviously heightened the interest in proteins intervening upstream formation of direct precursors of resolvins.

An important window to consider argan oil and ACOX1 as worthy regulators of inflammation perhaps lies in findings made in major disorders related to aging and known to involve inflammation. In this light, argan oil has been experimentally shown to be effective in blunting some of the features of diabetes and even in preventing chemically induced diabetes, displaying antihypertensive and antiproliferative properties, reducing in diabetic patients oxidation of LDL [71-74]. ACOX1 was found to be increased by compounds including FGF19 (Fibroblast growth factor 19, a hormonal gut-derived peptide) and nordihydroguaiaretic acid (a Creosote bush metabolite), which have been shown to improve metabolic syndrome $[75,76]$. Nordihydroguaiaretic acid is endowed with many biological properties including free 
radical scavenging, lipooxygenase inhibition, modulation of nuclear factor erythroid 2-related factor 2 (Nfr2)/antioxidant response element (ARE) signaling pathway, and cytoprotective and toxic properties towards normal and cancerous cells, respectively; this polyphenolic compound has also proven improvement in many disease conditions such as cancer, nephropathy, and neurodegenerative disorders (for valuable reviews, the reader may be kindly referred to $[77,78]$ ). In fact, nordihydroguaiaretic acid has been shown to counteract major events, leading to metabolic syndrome and, in this context, to protect liver metabolism, fading high-fat-dietinduced hypertriglyceridemia and hepatic steatosis ([76] and references therein). Among changes induced by the phenol compound is increased transcript expression for ACOX1, which has been considered for its metabolic oxidizing role as regards to protection given by nordihydroguaiaretic acid. However, taking into account the known role of inflammation in the development of steatosis (for a review, see [79]), protection given by nordihydroguaiaretate-induced ACOX1 against steatosis might result from anti-inflammatory properties of ACOX1. FGF19 is upregulated by farnesoid X receptor (FXR) and is physiologically involved in carbohydrate, bile, and fatty acid metabolism (for a review, see [80]). It improves glucose and lipid homeostasis and tissue response to insulin, favours weight control and energy metabolism, and as a whole has a beneficial impact in diabetes, heart and kidney diseases, and in obesity and metabolic syndrome [80]. All these aging-related disorders face both metabolic impairment and inflammation, and therefore the fact that ACOX1 is one of the target proteins upregulated by FGF19 [75], might, not only metabolically but also by antiinflammatory mechanisms, contribute to the health benefits attributed to FGF19. Recently, however, the therapeutic potential of stimulating FGF19 and related signaling has been shaded by showing mitogenic potential conveyed by part of FGF19 protein targets [75]. Additional understanding for the mechanisms specifically mediating metabolic effects and those specifically involved in proliferative effects of FGF19 is awaited in order to uncouple these effects to meet acceptable therapeutic development.

\section{SPM Protection in Aging-Related Disorders}

Aging is long known to reduce peroxisomal $\beta$-oxidation and to lower ACOX1 [81]. Interestingly also, aging is associated with an inflammation status notably resulting from a less efficacy of aging to resolve acute inflammation injuries [19]. This lowered effectiveness of the anti-inflammatory response has been shown to be associated with a drop in SPM formation [19]. Accordingly, age-related decline in resolving inflammation is corrected by providing SPM or one of their important precursors, DHA [19]. In aging and in several aging-related diseases, SPM deficiency and/or diseaseimprovement have been documented. Aging brain is protected by DHA and DHA-derived SPM (notably neuroprotectin D1) [34, 82-85], which also improve outcome of brain ischemia-reperfusion episodes [82-85]. DHA precursors, n-3 PUFAs, and DHA-derived SPM, neuroprotectin D1, improve mitochondrial dysfunction of senescent brain
[86]. In Alzheimer's disease and other degenerative disorders, DHA, SPM or SPM yield-enhancing strategies have proven efficacy in improving neuronal survival and inflammation-driven disease pathogenesis $[34,82,83,85$, 87-94]. Age-related retinal degeneration and vision disturbances have also been found to involve disturbances in DHA and SPM and to be protected by SPM through cell survival $[82,83,85,87,89,95]$. Brain ischemia/reperfusion and stroke may be improved by SPM-driven survival signaling and reduction in infiltrating leucocytes [82-84, 90]. Atherosclerosis has been also supported to be favourably modulated by SPM [96].

\section{Anti-Inflammatory Roles of Peroxisomal ACOX1 versus Mitochondrial $\beta$-Oxidation}

Most abundant fatty acids have a long and a straight carbon chain. When assessing the oxidation of these fatty acids as an energy-producing pathway, both mitochondrial and peroxisomal $\beta$-oxidation are considered, the former and the latter exhibiting major and minor contributions to overall fatty acid oxidation and the products of the latter being also potential substrates for the former. ACOX1, being the rate-limiting step in the peroxisomal oxidation of straight chain fatty acids, its activity is assayed to account for peroxisomal fatty acid oxidation capacity. Besides a limited role in energy production, ACOX1-driven peroxisomal $\beta$-oxidation, because taking place in the yield of potent anti-inflammatory metabolites, also plays a role in inflammation control as largely covered in this review. This role of ACOX1 remains, however, overlooked often in favor of its role in carbon-chain shortening and hence clearance of very long-chain fatty acids or in the contribution, even if minor, in energy production by ACOX1-driven peroxisomal $\beta$-oxidation. Whereas peroxisomal $\beta$-oxidation-driven protection against inflammation rests on generation of precursors for potent anti-inflammatory mediators, mitochondrial fatty acid oxidation-driven anti-inflammatory protection results from its capacity of removing proinflammatory compounds such as saturated fatty acids. These latter have been shown to promote insulin resistance, oxidative stress and oxidative damage and, in this respect, mitochondrial fatty acid oxidation meets anti-inflammatory function through avoidance of both ROS generation and lipotoxicity and through blunting of palmitate-induced proinflammatory cytokines, ER stress, and oxidative damage [97-102]. On the opposite, mitochondrial fatty acid oxidation may also promote inflammation through inflammasome activation and synthesis of the proinflammatory IL $1 \beta$ [103], making mitochondrial fatty acid oxidation, depending on the context, both inhibitor and stimulator of inflammation. In contrast to peroxisomal ACOX1-driven $\beta$-oxidation, mitochondrial fatty acid oxidation would not contribute to the synthesis of precursors for SPM. However, mitochondrial VLCAD (very long chain acyl-CoA dehydrogenase) and LCAD (long chain acyl-CoA dehydrogenase) $\mathrm{KO}$ mice have been described to exhibit tissue decrease in DHA (docosahexaenoic acid) levels [104], and whether this effect might result from a lack of contributing or regulatory effect of 
mitochondrial fatty acid oxidation or in turn interfering effect of mitochondrial enzyme deficiency through accumulating metabolites on DHA biosynthesis still remains to be elucidated. To our knowledge, SPM levels have still not been reported in peroxisomal and mitochondrial $\beta$ oxidation disorders.

Regarding the links between mitochondrial fatty acid oxidation and aging, age-dependent decrease in mitochondrial pathway [105], as well as either increase [106] or decrease [107] in CPT1 rate-limiting step have been reported. Age-dependent decrease of mitochondrial fatty acid oxidation has been shown to be dependent on age-related glutathione drop which also enhances ROS formation and promotes insulin resistance, these metabolic and signaling alterations being corrected by cysteine-based supplementations dedicated to restore intracellular glutathione stores [105]. Increased mitochondrial fatty acid oxidation might finally improve aging as for instance attested by its ability to alleviate age-related liver lipid accumulation [108].

\section{Conclusion}

Recent works on argan oil in prooxidative and inflammatory animal/human models provide a convergent sound support for the antioxidant/anti-inflammatory role of the peroxisomal enzyme, acyl-CoA oxidase type 1 (ACOX1). The model of LPS-driven toxicity and protection by argan oil has been transposed to model similarly aging inflammation also driven by reduced PGC1- $\alpha$ activity and also considered with a special emphasis on anti-inflammatory and hence antiaging key role of ACOX1. From the one hand, this view of ACOX1 is consistent with the key role played by peroxisomal ACOX1 in the production of precursor(s) for the synthesis of lipid mediators directly involved in the resolution of the inflammation process, and for this reason called resolvins. Resolvins and related compounds such as neuroprotectins and maresins are currently referred to as specialized proresolving mediators (SPM). On the other hand, aging and aging-related disorders are associated with reduced PGC1- $\alpha$ function, may be associated with reduced ACOX1 activity, lowered SPM levels, and delayed resolution of inflammation and may be improved by strategies rising ACOX1 (metabolic syndrome and diabetes) and SPM (brain and eye aging along with corresponding neurodegenerative disorders, atherosclerosis, and stroke). The strategical metabolic place occupied by ACOX1, upstream of SPM biosynthesis, along with ability of ACOX1 preservation/induction and of SPM to improve aging-related disorders and with the fact that aging is characterized by a drop in ACOX1 and SPM, all argue towards the view that ACOX1 represents a previously unsuspected and currently emerging antiaging protein.

\section{Conflicts of Interest}

The authors declare that there are no conflicts of interest.

\section{Acknowledgments}

This work was supported by the Action Intégrée of the Comité Mixte Inter-universitaire Franco-Marocain (CMIFM, AIMA/14/310, Campus France) from the PHC Volubilis/ Toubkal program (No30293PA), Ministry of Foreign Affairs, The Centre National Pour la Recherche Scientifique et Technique (CNRST) Morocco, the Conseil Régional de Bourgogne (PARI2012:A324; PARI2013:B135; CPS0009) and the Ministère de l'enseignement et de la Recherche (crédits récurrents). The authors would like to acknowledge networking support by the COST (European Cooperation in Science and Technology) Action CA 16112 NutRedOx (Personalized Nutrition in aging society: redox control of major age-related diseases).

\section{References}

[1] J. H. Diaz, "Poisoning by herbs and plants: rapid toxidromic classification and diagnosis," Wilderness \& Environmental Medicine, vol. 27, no. 1, pp. 136-152, 2016.

[2] J. B. Lingrel, "The physiological significance of the cardiotonic steroid/ouabain-binding site of the Na,K-ATPase," Annual Review of Physiology, vol. 72, no. 1, pp. 395-412, 2010.

[3] S. Man, W. Gao, C. Wei, and C. Liu, "Anticancer drugs from traditional toxic Chinese medicines," Phytotherapy Research, vol. 26, no. 10, pp. 1449-1465, 2012.

[4] T. J. Lybbert, A. Aboudrare, D. Chaloud, N. Magnan, and M. Nash, "Booming markets for Moroccan argan oil appear to benefit some rural households while threatening the endemic argan forest," Proceedings of the National Academy of Sciences of the United States of America, vol. 108, no. 34, pp. 13963-13968, 2011.

[5] R. Ostan, M. C. Béné, L. Spazzafumo et al., "Impact of diet and nutraceutical supplementation on inflammation in elderly people. Results from the RISTOMED study, an openlabel randomized control trial," Clinical Nutrition, vol. 35, no. 4, pp. 812-818, 2016.

[6] R. El Kebbaj, P. Andreoletti, H. I. El Hajj et al., "Argan oil prevents down-regulation induced by endotoxin on liver fatty acid oxidation and gluconeogenesis and on peroxisome proliferator-activated receptor gamma coactivator- $1 \alpha$, (PGC$1 \alpha)$, peroxisome proliferator-activated receptor $\alpha(\operatorname{PPAR} \alpha)$ and estrogen related receptor $\alpha(\operatorname{ERR} \alpha)$," Biochimie Open, vol. 1, pp. 51-59, 2015.

[7] S. Ferdinandusse, S. Denis, P. A. Mooijer et al., "Identification of the peroxisomal beta-oxidation enzymes involved in the biosynthesis of docosahexaenoic acid," Journal of Lipid Research, vol. 42, no. 12, pp. 1987-1995, 2001.

[8] S. K. Orr and R. P. Bazinet, "The emerging role of docosahexaenoic acid in neuroinflammation," Current Opinion in Investigational Drugs, vol. 9, no. 7, pp. 735-743, 2008.

[9] C. N. Serhan, N. Chiang, J. Dalli, and B. D. Levy, "Lipid mediators in the resolution of inflammation," Cold Spring Harbor Perspectives in Biology, vol. 7, no. 2, article a016311, 2014.

[10] R. El Kebbaj, S. El Kamouni, H. I. El Hajj et al., "Modulation of peroxisomes abundance by argan oil and lipopolysaccharides in acyl-CoA oxidase 1-deficient fibroblasts," Health, vol. 5, no. 1, article 26522, 2013. 
[11] H. Berrougui, M. Cloutier, M. Isabelle, and A. Khalil, "Phenolic-extract from argan oil (Argania spinosa L.) inhibits human low-density lipoprotein (LDL) oxidation and enhances cholesterol efflux from human THP-1 macrophages," Atherosclerosis, vol. 184, no. 2, pp. 389-396, 2006.

[12] S. El Kamouni, R. El Kebbaj, P. Andreoletti et al., "Protective effect of argan and olive oils against LPS-induced oxidative stress and inflammation in mice livers," International Journal of Molecular Sciences, vol. 18, no. 10, article 2181, 2017.

[13] L. Gurcel, L. Abrami, S. Girardin, J. Tschopp, and F. G. van der Goot, "Caspase-1 activation of lipid metabolic pathways in response to bacterial pore-forming toxins promotes cell survival," Cell, vol. 126, no. 6, pp. 1135-1145, 2006.

[14] K. Ishimoto, H. Nakamura, K. Tachibana et al., "Sterolmediated regulation of human lipin 1 gene expression in hepatoblastoma cells," Journal of Biological Chemistry, vol. 284, no. 33, pp. 22195-22205, 2009.

[15] M. C. Sugden, P. W. Caton, and M. J. Holness, "PPAR control: it's SIRTainly as easy as PGC," Journal of Endocrinology, vol. 204, no. 2, pp. 93-104, 2010.

[16] C. Zhang, A. A. Wendel, M. R. Keogh, T. E. Harris, J. Chen, and R. A. Coleman, "Glycerolipid signals alter mTOR complex 2 (mTORC2) to diminish insulin signaling," Proceedings of the National Academy of Sciences of the United States of America, vol. 109, no. 5, pp. 16671672, 2012.

[17] G. S. Dhaunsi, C. D. Hanevold, and I. Singh, "Impairment of peroxisomal $\beta$-oxidation system by endotoxin treatment," Molecular and Cellular Biochemistry, vol. 135, no. 2, pp. 187-193, 1994.

[18] J. Schilling, L. Lai, N. Sambandam, C. E. Dey, T. C. Leone, and D. P. Kelly, "Toll-like receptor-mediated inflammatory signaling reprograms cardiac energy metabolism by repressing peroxisome proliferator-activated receptor $\gamma$ coactivator-1 signaling," Circulation: Heart Failure, vol. 4, no. 4, pp. 474482, 2011.

[19] H. H. Arnardottir, J. Dalli, R. A. Colas, M. Shinohara, and C. N. Serhan, "Aging delays resolution of acute inflammation in mice: reprogramming the host response with novel nano-proresolving medicines," The Journal of Immunology, vol. 193, no. 8, pp. 4235-4244, 2014.

[20] T. Wenz, "Mitochondria and PGC- $1 \alpha$ in aging and ageassociated diseases," Journal of Aging Research, vol. 2011, Article ID 810619, 12 pages, 2011.

[21] M. E. Patti, A. J. Butte, S. Crunkhorn et al., "Coordinated reduction of genes of oxidative metabolism in humans with insulin resistance and diabetes: potential role of PGC1 and NRF1," Proceedings of the National Academy of Sciences of the United States of America, vol. 100, no. 14, pp. 84668471, 2003.

[22] H. Zhang, S.-Y. Zhang, C. Jiang et al., "Intermedin/adrenomedullin 2 polypeptide promotes adipose tissue browning and reduces high-fat diet-induced obesity and insulin resistance in mice," International Journal of Obesity, vol. 40, no. 5, pp. 852-860, 2016.

[23] A. O. Kadlec, D. S. Chabowski, K. Ait-Aissa et al., "PGC-1 $\alpha$ (peroxisome proliferator-activated receptor $\gamma$ coactivator 1$\alpha$ ) overexpression in coronary artery disease recruits $\mathrm{NO}$ and hydrogen peroxide during flow-mediated dilation and protects against increased intraluminal pressure," Hypertension, vol. 70, no. 1, pp. 166-173, 2017.
[24] M. Sajan, B. Hansen, R. Ivey III et al., "Brain insulin signaling is increased in insulin-resistant states and decreases in FOXOs and PGC- $1 \alpha$ and increases in $\mathrm{A} \beta 1-_{40 / 42}$ and phospho-tau may abet Alzheimer development," Diabetes, vol. 65, no. 7, pp. 1892-1903, 2016.

[25] G. Sweeney and J. Song, "The association between PGC-1 $\alpha$ and Alzheimer's disease," Anatomy \& Cell Biology, vol. 49, no. 1, pp. 1-6, 2016.

[26] H. Jiang, S. U. Kang, S. Zhang et al., "Adult conditional knockout of PGC- $1 \alpha$ leads to loss of dopamine neurons," eNeuro, vol. 3, no. 4, 2016.

[27] C. H. Ng, A. H. Basil, L. Hang et al., "Genetic or pharmacological activation of the Drosophila PGC- $1 \alpha$ ortholog spargel rescues the disease phenotypes of genetic models of Parkinson's disease," Neurobiology of Aging, vol. 55, pp. 33-37, 2017.

[28] A. Siddiqui, A. Rane, S. Rajagopalan, S. J. Chinta, and J. K. Andersen, "Detrimental effects of oxidative losses in parkin activity in a model of sporadic Parkinson's disease are attenuated by restoration of PGC1alpha," Neurobiology of Disease, vol. 93, pp. 115-120, 2016.

[29] L. Cui, H. Jeong, F. Borovecki, C. N. Parkhurst, N. Tanese, and D. Krainc, "Transcriptional repression of PGC- $1 \alpha$ by mutant huntingtin leads to mitochondrial dysfunction and neurodegeneration," Cell, vol. 127, no. 1, pp. 59-69, 2006.

[30] S. Jesse, H. Bayer, M. C. Alupei et al., "Ribosomal transcription is regulated by PGC-1alpha and disturbed in Huntington's disease," Scientific Reports, vol. 7, no. 1, p. 8513, 2017.

[31] P. Weydt, V. V. Pineda, A. E. Torrence et al., "Thermoregulatory and metabolic defects in Huntington's disease transgenic mice implicate PGC- $1 \alpha$ in Huntington's disease neurodegeneration," Cell Metabolism, vol. 4, no. 5, pp. 349-362, 2006.

[32] Ó. Fabregat-Andrés, F. Ridocci-Soriano, J. Estornell-Erill et al., "Blood PGC- $1 \alpha$ concentration predicts myocardial salvage and ventricular remodeling after ST-segment elevation acute myocardial infarction," Revista Española de Cardiología (English Edition), vol. 68, no. 5, pp. 408-416, 2015.

[33] H. F. Pei, J. N. Hou, F. P. Wei et al., "Melatonin attenuates postmyocardial infarction injury via increasing Tom70 expression," Journal of Pineal Research, vol. 62, no. 1, article e12371, 2017.

[34] D. Sun and F. Yang, "Metformin improves cardiac function in mice with heart failure after myocardial infarction by regulating mitochondrial energy metabolism," Biochemical and Biophysical Research Communications, vol. 486, no. 2, pp. 329-335, 2017.

[35] L. Tao, Y. Bei, S. Lin et al., "Exercise training protects against acute myocardial infarction via improving myocardial energy metabolism and mitochondrial biogenesis," Cellular Physiology and Biochemistry, vol. 37, no. 1, pp. 162-175, 2015.

[36] Z. Wang, J. Ding, X. Luo et al., "Effect of allopurinol on myocardial energy metabolism in chronic heart failure rats after myocardial infarct," International Heart Journal, vol. 57, no. 6, pp. 753-759, 2016.

[37] W. Yan, H. Zhang, P. Liu et al., "Impaired mitochondrial biogenesis due to dysfunctional adiponectin-AMPK-PGC$1 \alpha$ signaling contributing to increased vulnerability in diabetic heart," Basic Research in Cardiology, vol. 108, no. 3, p. 329, 2013. 
[38] S. Camandola and M. P. Mattson, "Brain metabolism in health, aging, and neurodegeneration," EMBO Journal, vol. 36, no. 11, pp. 1474-1492, 2017.

[39] K. Róna-Vörös and P. Weydt, "The role of PGC-1 $\alpha$ in the pathogenesis of neurodegenerative disorders," Current Drug Targets, vol. 11, no. 10, pp. 1262-1269, 2010.

[40] S. M. Craige, S. Kröller-Schön, C. Li et al., "PGC- $1 \alpha$ dictates endothelial function through regulation of eNOS expression," Scientific Reports, vol. 6, no. 1, article 38210, 2016.

[41] A. O. Kadlec, D. S. Chabowski, K. Ait-Aissa, and D. D. Gutterman, "Role of PGC- $1 \alpha$ in vascular regulation: implications for atherosclerosis," Arteriosclerosis, Thrombosis, and Vascular Biology, vol. 36, no. 8, pp. 1467-1474, 2016.

[42] A. S. Ryan, G. Li, C. Hafer-Macko, and F. M. Ivey, "Resistive training and molecular regulators of vascular-metabolic risk in chronic stroke," Journal of Stroke and Cerebrovascular Diseases, vol. 26, no. 5, pp. 962-968, 2017.

[43] Y. You, Y. Hou, X. Zhai et al., "Protective effects of PGC- $1 \alpha$ via the mitochondrial pathway in rat brains after intracerebral hemorrhage," Brain Research, vol. 1646, pp. 34-43, 2016.

[44] M. Cherkaoui-Malki, S. Surapureddi, H. I. El-Hajj, J. Vamecq, and P. Andreoletti, "Hepatic steatosis and peroxisomal fatty acid beta-oxidation," Current Drug Metabolism, vol. 13, no. 10, pp. 1412-1421, 2012.

[45] R. J. A. Wanders, "Peroxisomes, lipid metabolism, and peroxisomal disorders," Molecular Genetics and Metabolism, vol. 83, no. 1-2, pp. 16-27, 2004.

[46] S. Ferdinandusse, S. Denis, C. W. T. van Roermund et al., "A novel case of ACOX2 deficiency leads to recognition of a third human peroxisomal acyl-CoA oxidase," Biochimica et Biophysica Acta (BBA) - Molecular Basis of Disease, vol. 1864, no. 3, pp. 952-958.

[47] C. Y. Fan, J. Pan, N. Usuda, A. V. Yeldandi, M. S. Rao, and J. K. Reddy, "Steatohepatitis, spontaneous peroxisome proliferation and liver tumors in mice lacking peroxisomal fatty acyl-CoA oxidase. Implications for peroxisome proliferatoractivated receptor $\alpha$ natural ligand metabolism," Journal of Biological Chemistry, vol. 273, no. 25, pp. 15639-15645, 1998.

[48] J. Huang, N. Viswakarma, S. Yu et al., "progressive endoplasmic reticulum stress contributes to hepatocarcinogenesis in fatty Acyl-CoA oxidase 1-deficient mice," American Journal of Pathology, vol. 179, no. 2, pp. 703-713, 2011.

[49] A. Vluggens, P. Andreoletti, N. Viswakarma et al., "Functional significance of the two ACOX1 isoforms and their crosstalks with PPAR $\alpha$ and $\operatorname{RXR} \alpha$," Laboratory Investigation, vol. 90, no. 5, pp. 696-708, 2010.

[50] S. S. Lee, T. Pineau, J. Drago et al., "Targeted disruption of the alpha isoform of the peroxisome proliferator-activated receptor gene in mice results in abolishment of the pleiotropic effects of peroxisome proliferators," Molecular and Cellular Biology, vol. 15, no. 6, pp. 3012-3022, 1995.

[51] F. S. Eichler, J. Q. Ren, M. Cossoy et al., "Is microglial apoptosis an early pathogenic change in cerebral X-linked adrenoleukodystrophy?," Annals of Neurology, vol. 63, no. 6, pp. 729-742, 2008.

[52] H. I. El Hajj, A. Vluggens, P. Andreoletti et al., "The inflammatory response in acyl-CoA oxidase 1 deficiency (pseudoneonatal adrenoleukodystrophy)," Endocrinology, vol. 153, no. 6, pp. 2568-2575, 2012.

[53] A. S. Paintlia, A. G. Gilg, M. Khan, A. K. Singh, E. Barbosa, and I. Singh, "Correlation of very long chain fatty acid accumulation and inflammatory disease progression in childhood X-ALD: implications for potential therapies," Neurobiology of Disease, vol. 14, no. 3, pp. 425-439, 2003.

[54] H. Guillou, D. Zadravec, P. G. P. Martin, and A. Jacobsson, "The key roles of elongases and desaturases in mammalian fatty acid metabolism: insights from transgenic mice," Progress in Lipid Research, vol. 49, no. 2, pp. 186-199, 2010.

[55] E. Christensen, B. Woldseth, T.-A. Hagve et al., "Peroxisomal $\beta$-oxidation of polyunsaturated long chain fatty acids in human fibroblasts. The polyunsaturated and the saturated long chain fatty acids are retroconverted by the same acylCoA oxidase," Scandinavian Journal of Clinical and Laboratory Investigation, vol. 53, no. sup215, pp. 61-74, 1993.

[56] M. Grønn, E. Christensen, T. A. Hagve, and B. O. Christophersen, "Peroxisomal retroconversion of docosahexaenoic acid $(22: 6(n-3))$ to eicosapentaenoic acid $(20: 5(n-3))$ studied in isolated rat liver cells," Biochimica et Biophysica Acta (BBA) - Lipids and Lipid Metabolism, vol. 1081, no. 1, pp. 85-91, 1991.

[57] T. A. Hagve and B. O. Christophersen, "Evidence for peroxisomal retroconversion of adrenic acid $(22: 4(n-6))$ and docosahexaenoic acids (22:6(n-3)) in isolated liver cells," Biochimica et Biophysica Acta (BBA) - Lipids and Lipid Metabolism, vol. 875, no. 2, pp. 165-173, 1986.

[58] S. A. Moore, E. Hurt, E. Yoder, H. Sprecher, and A. A. Spector, "Docosahexaenoic acid synthesis in human skin fibroblasts involves peroxisomal retroconversion of tetracosahexaenoic acid," Journal of Lipid Research, vol. 36, no. 11, pp. 2433-2443, 1995.

[59] H. M. Su, A. B. Moser, H. W. Moser, and P. A. Watkins, "Peroxisomal straight-chain acyl-CoA oxidase and Dbifunctional protein are essential for the retroconversion step in docosahexaenoic acid synthesis," Journal of Biological Chemistry, vol. 276, no. 41, pp. 38115-38120, 2001.

[60] S. Nicosia and C. Patrono, "Eicosanoid biosynthesis and action: novel opportunities for pharmacological intervention," FASEB Journal, vol. 3, no. 8, pp. 1941-1948, 1989.

[61] H. Tapiero, G. Nguyen Ba, P. Couvreur, and K. D. Tew, "Polyunsaturated fatty acids (PUFA) and eicosanoids in human health and pathologies," Biomedicine \& Pharmacotherapy, vol. 56, no. 5, pp. 215-222, 2002.

[62] V. A. Ziboh, C. C. Miller, and Y. Cho, "Metabolism of polyunsaturated fatty acids by skin epidermal enzymes: generation of antiinflammatory and antiproliferative metabolites," American Journal of Clinical Nutrition, vol. 71, 1 Supplement, pp. 361S-366S, 2000.

[63] H. R. Waterham, S. Ferdinandusse, and R. J. A. Wanders, "Human disorders of peroxisome metabolism and biogenesis," Biochimica et Biophysica Acta (BBA) - Molecular Cell Research, vol. 1863, no. 5, pp. 922-933, 2016.

[64] C. Boudrault, R. P. Bazinet, and D. W. L. Ma, "Experimental models and mechanisms underlying the protective effects of n-3 polyunsaturated fatty acids in Alzheimer's disease," The Journal of Nutritional Biochemistry, vol. 20, no. 1, pp. 1-10, 2009.

[65] W. J. Lukiw and N. G. Bazan, "Docosahexaenoic acid and the aging brain," The Journal of Nutrition, vol. 138, no. 12, pp. 2510-2514, 2008.

[66] N. G. Bazan, "Survival signaling in retinal pigment epithelial cells in response to oxidative stress: significance in retinal degenerations," Advances in Experimental Medicine and Biology, vol. 572, pp. 531-540, 2006. 
[67] C. M. Yates, P. C. Calder, and G. Ed Rainger, "Pharmacology and therapeutics of omega-3 polyunsaturated fatty acids in chronic inflammatory disease," Pharmacology \& Therapeutics, vol. 141, no. 3, pp. 272-282, 2014.

[68] H. G. Park, W. J. Park, K. S. D. Kothapalli, and J. Thomas Brenna, "The fatty acid desaturase 2 (FADS2) gene product catalyzes $\Delta 4$ desaturation to yield n-3 docosahexaenoic acid and n-6 docosapentaenoic acid in human cells," The FASEB Journal, vol. 29, no. 9, pp. 3911-3919, 2015.

[69] J. P. Infante, C. L. Tschanz, N. Shaw, A. L. Michaud, P. Lawrence, and J. T. Brenna, "Straight-chain acyl-CoA oxidase knockout mouse accumulates extremely long chain fatty acids from $\alpha$-linolenic acid: evidence for runaway carouseltype enzyme kinetics in peroxisomal $\beta$-oxidation diseases," Molecular Genetics and Metabolism, vol. 75, no. 2, pp. 108119, 2002.

[70] Q. Qu, W. Xuan, and G. H. Fan, "Roles of resolvins in the resolution of acute inflammation," Cell Biology International, vol. 39, no. 1, pp. 3-22, 2015.

[71] S. Bellahcen, Z. Hakkou, A. Ziyyat et al., "Antidiabetic and antihypertensive effect of virgin argan oil in model of neonatal streptozotocin-induced diabetic and l-nitroarginine methylester (l-NAME) hypertensive rats," Journal of Complementary and Integrative Medicine, vol. 10, no. 1, 2013.

[72] S. Bellahcen, H. Mekhfi, A. Ziyyat et al., "Prevention of chemically induced diabetes mellitus in experimental animals by virgin argan oil," Phytotherapy Research, vol. 26, no. 2, pp. 180-185, 2012.

[73] M. M. Ould Mohamedou, K. Zouirech, M. El Messal, M. S. El Kebbaj, A. Chraibi, and A. Adlouni, "Argan oil exerts an antiatherogenic effect by improving lipids and susceptibility of LDL to oxidation in type 2 diabetes patients," International Journal of Endocrinology, vol. 2011, Article ID 747835, 8 pages, 2011.

[74] S. Samane, J. Noël, Z. Charrouf, H. Amarouch, and P. S. Haddad, "Insulin-sensitizing and anti-proliferative effects of Argania spinosa seed extracts," Evidence-based Complementary and Alternative Medicine, vol. 3, no. 3, pp. 317327, 2006.

[75] V. Massafra, A. Milona, H. R. Vos, B. M. T. Burgering, and S. W. C. van Mil, "Quantitative liver proteomics identifies FGF19 targets that couple metabolism and proliferation," PLoS One, vol. 12, no. 2, article e0171185, 2017.

[76] H. Zhang, Y. Li, J. Hu et al., "Effect of creosote bush-derived NDGA on expression of genes involved in lipid metabolism in liver of high-fructose fed rats: relevance to NDGA amelioration of hypertriglyceridemia and hepatic steatosis," PLoS One, vol. 10, no. 9, article e0138203, 2015.

[77] J. Hernández-Damián, A. C. Andérica-Romero, and J. Pedraza-Chaverri, "Paradoxical cellular effects and biological role of the multifaceted compound nordihydroguaiaretic acid," Archiv der Pharmazie, vol. 347, no. 10, pp. 685-697, 2014.

[78] J. M. Lü, J. Nurko, S. M. Weakley et al., "Molecular mechanisms and clinical applications of nordihydroguaiaretic acid (NDGA) and its derivatives: an update," Medical Science Monitor, vol. 16, no. 5, pp. RA93-R100, 2010.

[79] W. Peverill, L. Powell, and R. Skoien, "Evolving concepts in the pathogenesis of NASH: beyond steatosis and inflammation," International Journal of Molecular Sciences, vol. 15, no. 12, pp. 8591-8638, 2014.
[80] F. Zhang, L. Yu, X. Lin et al., "Minireview: roles of fibroblast growth factors 19 and 21 in metabolic regulation and chronic diseases," Molecular Endocrinology, vol. 29, no. 10, pp. 14001413, 2015.

[81] R. Périchon, J. M. Bourre, J. F. Kelly, and G. S. Roth, “The role of peroxisomes in aging," Cellular and Molecular Life Sciences (CMLS), vol. 54, no. 7, pp. 641-652, 1998.

[82] N. G. Bazan, "Cellular and molecular events mediated by docosahexaenoic acid-derived neuroprotectin D1 signaling in photoreceptor cell survival and brain protection," Prostaglandins, Leukotrienes and Essential Fatty Acids, vol. 81, no. 2-3, pp. 205-211, 2009.

[83] N. G. Bazan, "Neuroprotectin D1-mediated antiinflammatory and survival signaling in stroke, retinal degenerations, and Alzheimer's disease," Journal of Lipid Research, vol. 50, Supplement, pp. S400-S405, 2009.

[84] F. Echeverría, R. Valenzuela, M. Catalina Hernandez-Rodas, and A. Valenzuela, "Docosahexaenoic acid (DHA), a fundamental fatty acid for the brain: new dietary sources," Prostaglandins, Leukotrienes and Essential Fatty Acids, vol. 124, pp. 1-10, 2017.

[85] P. K. Mukherjee, A. Chawla, M. S. Loayza, and N. G. Bazan, "Docosanoids are multifunctional regulators of neural cell integrity and fate: significance in aging and disease," Prostaglandins, Leukotrienes and Essential Fatty Acids, vol. 77, no. 5-6, pp. 233-238, 2007.

[86] S. Afshordel, S. Hagl, D. Werner et al., "Omega-3 polyunsaturated fatty acids improve mitochondrial dysfunction in brain aging - impact of Bcl-2 and NPD-1 like metabolites," Prostaglandins, Leukotrienes and Essential Fatty Acids (PLEFA), vol. 92, pp. 23-31, 2015.

[87] N. G. Bazan, M. F. Molina, and W. C. Gordon, "Docosahexaenoic acid signalolipidomics in nutrition: significance in aging, neuroinflammation, macular degeneration, Alzheimer's, and other neurodegenerative diseases," Annual Review of Nutrition, vol. 31, no. 1, pp. 321-351, 2011.

[88] M. Fiala, N. Terrando, and J. Dalli, "Specialized pro-resolving mediators from omega-3 fatty acids improve amyloid- $\beta$ phagocytosis and regulate inflammation in patients with minor cognitive impairment," Journal of Alzheimer's Disease, vol. 48, no. 2, pp. 293-301, 2015.

[89] W. J. Lukiw and N. G. Bazan, "Inflammatory, apoptotic, and survival gene signaling in Alzheimer's disease. A review on the bioactivity of neuroprotectin D1 and apoptosis," Molecular Neurobiology, vol. 42, no. 1, pp. 10-16, 2010.

[90] R. Palacios-Pelaez, W. J. Lukiw, and N. G. Bazan, "Omega-3 essential fatty acids modulate initiation and progression of neurodegenerative disease," Molecular Neurobiology, vol. 41, no. 2-3, pp. 367-374, 2010.

[91] C. Zhang and N. G. Bazan, "Lipid-mediated cell signaling protects against injury and neurodegeneration', Journal of Nutrition, vol. 140, no. 4, pp. 858-863, 2010.

[92] Y. Zhao, S. Bhattacharjee, B. M. Jones, J. Hill, P. Dua, and W. J. Lukiw, "Regulation of neurotropic signaling by the inducible, NF-kB-sensitive miRNA-125b in Alzheimer's disease $(\mathrm{AD})$ and in primary human neuronal-glial (HNG) cells," Molecular Neurobiology, vol. 50, no. 1, pp. 97-106, 2014.

[93] Y. Zhao, F. Calon, C. Julien et al., "Docosahexaenoic acidderived neuroprotectin D1 induces neuronal survival via secretase- and PPAR $\gamma$-mediated mechanisms in Alzheimer's disease models," PLoS One, vol. 6, no. 1, article e15816, 2011. 
[94] M. Zhu, X. Wang, E. Hjorth et al., "Pro-resolving lipid mediators improve neuronal survival and increase $\mathrm{A} \beta_{42}$ phagocytosis," Molecular Neurobiology, vol. 53, no. 4, pp. 2733-2749, 2016.

[95] N. G. Bazan, "Neurotrophins induce neuroprotective signaling in the retinal pigment epithelial cell by activating the synthesis $\mathrm{nl}$ of the anti-inflammatory and anti-apoptotic neuroprotectin D1," Advances in Experimental Medicine and Biology, vol. 613, pp. 39-44, 2008.

[96] G. Fredman and I. Tabas, "Boosting inflammation resolution in atherosclerosis: the next frontier for therapy," The American Journal of Patholology, vol. 187, no. 6, pp. 1211-1221, 2017.

[97] C. R. Bruce, A. J. Hoy, N. Turner et al., "Overexpression of carnitine palmitoyltransferase-1 in skeletal muscle is sufficient to enhance fatty acid oxidation and improve high-fat diet-induced insulin resistance," Diabetes, vol. 58, no. 3, pp. 550-558, 2009.

[98] D. Namgaladze and B. Brüne, "Macrophage fatty acid oxidation and its roles in macrophage polarization and fatty acid-induced inflammation," Biochimica et Biophysica Acta (BBA) - Molecular and Cell Biology of Lipids, vol. 1861, no. 11, pp. 1796-1807, 2016.

[99] D. Namgaladze, S. Lips, T. J. Leiker et al., "Inhibition of macrophage fatty acid $\beta$-oxidation exacerbates palmitate-induced inflammatory and endoplasmic reticulum stress responses," Diabetologia, vol. 57, no. 5, pp. 1067-1077, 2014.

[100] M. I. Malandrino, R. Fucho, M. Weber et al., "Enhanced fatty acid oxidation in adipocytes and macrophages reduces lipid-induced triglyceride accumulation and inflammation," American Journal of Physiology-Endocrinology and Metabolism, vol. 308, no. 9, pp. E756-E769, 2015.

[101] J. M. Orellana-Gavaldà, L. Herrero, M. I. Malandrino et al., "Molecular therapy for obesity and diabetes based on a long-term increase in hepatic fatty-acid oxidation," Hepatology, vol. 53, no. 3, pp. 821-832, 2011.

[102] D. Sebastián, L. Herrero, D. Serra, G. Asins, and F. G. Hegardt, "CPT I overexpression protects L6E9 muscle cells from fatty acid-induced insulin resistance," American Journal of Physiology-Endocrinology and Metabolism, vol. 292, no. 3, pp. E677-E686, 2007.

[103] J. S. Moon, K. Nakahira, K. P. Chung et al., "NOX4-dependent fatty acid oxidation promotes NLRP3 inflammasome activation in macrophages," Nature Medicine, vol. 22, no. 9, pp. 1002-1012, 2016.

[104] S. M. Houten, S. Violante, F. V. Ventura, and R. J. A. Wanders, "The biochemistry and physiology of mitochondrial fatty acid $\beta$-oxidation and its genetic disorders," Annual Review of Physiology, vol. 78, no. 1, pp. 23-44, 2016.

[105] D. Nguyen, S. L. Samson, V. T. Reddy, E. V. Gonzalez, and R. V. Sekhar, "Impaired mitochondrial fatty acid oxidation and insulin resistance in aging: novel protective role of glutathione," Aging Cell, vol. 12, no. 3, pp. 415-425, 2013.

[106] L. Zhao, X. Zou, Z. Feng et al., "Evidence for association of mitochondrial metabolism alteration with lipid accumulation in aging rats," Experimental Gerontology, vol. 56, pp. 3-12, 2014.
[107] R. H. Houtkooper, C. Argmann, S. M. Houten et al., "The metabolic footprint of aging in mice," Science Reports, vol. 1, no. 1, p. 134, 2011.

[108] H. J. An, B. Lee, S. M. Kim et al., "A PPAR pan agonist, MHY2013 alleviates age-related hepatic lipid accumulation by promoting fatty acid oxidation and suppressing inflammation," Biological \& Pharmaceutical Bulletin, vol. 41, no. 1, pp. 29-35, 2018. 


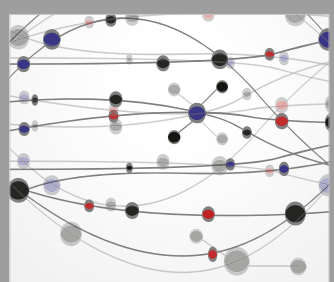

The Scientific World Journal
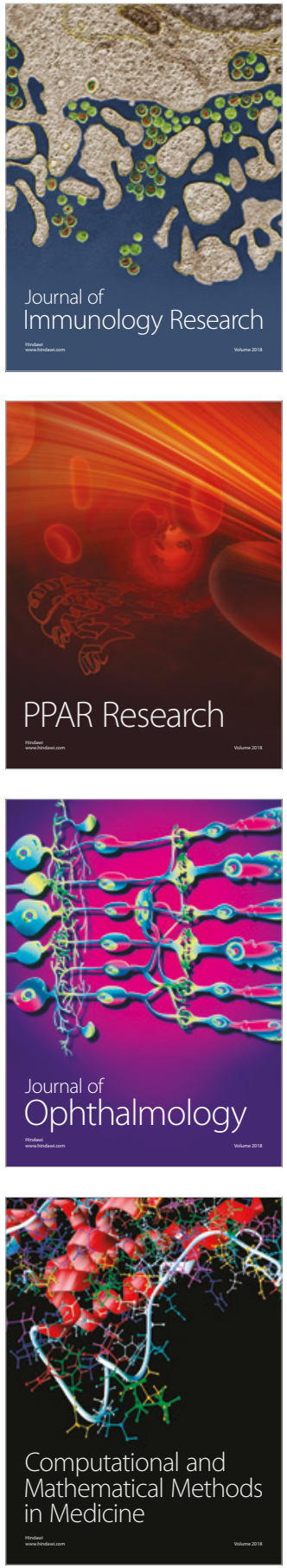

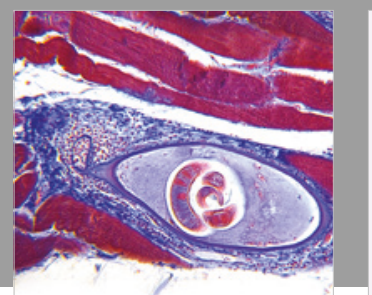

Gastroenterology Research and Practice

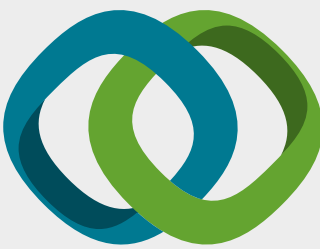

\section{Hindawi}

Submit your manuscripts at

www.hindawi.com
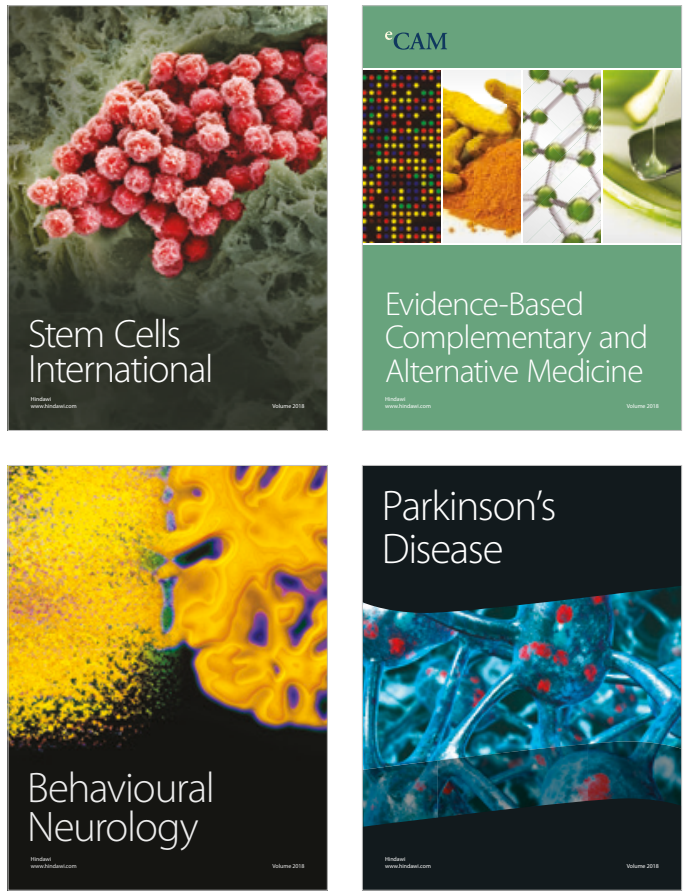

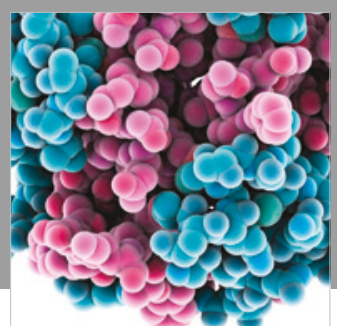

ournal of

Diabetes Research

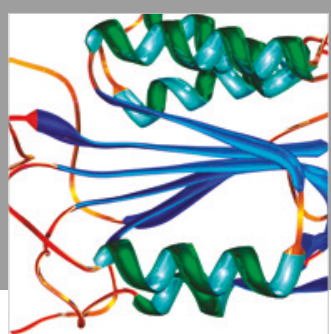

Disease Markers
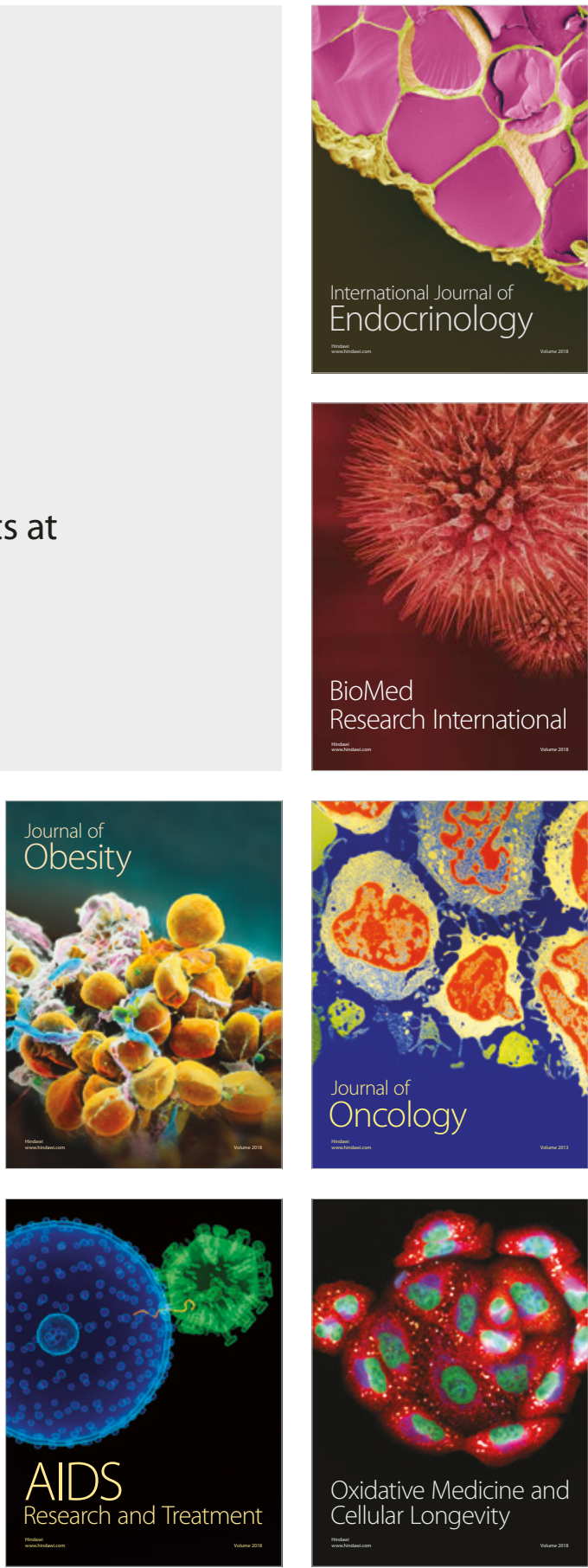